Катя Исса

University of Architecture, Civil Engineering and Geodesy, Sofia katyaissa@abv.bg

\title{
НАГЛАСИ НА ДНЕШНИТЕ БЪЛГАРСКИ ЕМИГРАНТИ КЫМ РОДНИЯ ЕЗИК И РОДНОТО ОБРАЗОВАНИЕ
}

Сред множеството определения на нагласите в теориите на различни научни дисциплини се открояват дадените от психологията, защото нагласата е психологически конструкт, абстракция, която не може да бъде директно наблюдавана, затова изследването ѝ най-често се извършва чрез анкетиране. Напоследък българското езикознание се занимава подробно с нагласите във връзка със социолингвистичната вариантност (най-вече в трудовете на Красимира Алексова). Авторката правилно посочва, „че най-същественият проблем, подчертаван в множество изследвания, е връзката на нагласите с реалното поведение“ [Алексова 2016: 80]. Затова нагласите на многобройните български емигранти, пръснати на териториите на всички континенти, към нашия език и към неговата употреба зад граница са от особено значение за българската държавна и езикова политика по отношение на емиграцията. Разбира се, анкетното проучване винаги крие рискове: „съществен проблем е даването на социално желателни отговори от респондентите. Според моя опит в провеждането на анкетни проучвания, - пише Алексова - а и опита на мои колеги [...] тази „заплаха“ съществува у нас не само при прилагане на директния подход към нагласите. Случва се анкетираните да отговорят не това, което действително мислят, а това, което смятат, че е редно да се каже. От съществена важност в този случай е изследователят да проучи предварително какви стереотипи, а и предразсъдъци са вкоренени в една група или общност“" [Алексова 2016: 83].

Обект на моето мащабно изследване е българската общност в Сидни, Австралия. Нагласите към използване на родния ни език и към неговото изучаване в училище бяха само част от проучването, наред с установените интерференции между българския език и официалния английски, алгоритъма на деформацията върху първия език, затихването на функциите му, степента на забравянето му от децата, емигрирали в предучилищна възраст и на владеенето му от децата, родени там. За установяване на нагласите към 
българския език в Сидни беше проведена анкета през лятото на 2016 г., успоредно с теренно проучване, състоящо се в скрити записи на територията на Неделното училище, в домовете на българи, живеещи в Сидни, и на срещи на българи на други места - в читалище, в заведение, в зъболекарски кабинет, на разходки. Проучването продължи 46 дена, а анкетните листове като сьпьтстваща дейност бяха предавани на ръка на желаещите, а също така бяха изпратени по електронните пощи на всички (400 на брой) членове на Българското патриотично дружество „Родина“. Тази анкета наричам „Първа““. Тук (съвсем произволно) представям един попълнен неин вариант (табл. 1):

Таблица 1. АНКЕТЕН ЛИСТ

Внимание: Не пишете името си и не се подписвайте!

\begin{tabular}{|c|c|c|}
\hline 1 & Страна и град, в който сега живеете. & Австралия, Gold Coast \\
\hline 2 & От колко време сте тук за постоянно? & От средата на 1992 \\
\hline 3 & $\begin{array}{l}\text { Живели ли сте другаде в чужбина, кога } \\
\text { и за колко време? }\end{array}$ & Не, никога \\
\hline 4 & От кое българско селище сте дошли? & От София \\
\hline 5 & Възраст. & 58 \\
\hline 6 & Пол. & Женски \\
\hline 7 & Образование (какво) и къде е получено? & Flinders University, Adelaide \\
\hline 8 & Професия. & Медицинска сестра \\
\hline 9 & $\begin{array}{l}\text { С каква работа сега изкарвате прехрана- } \\
\text { та си? }\end{array}$ & Като медицинска сестра \\
\hline 10 & Семейно положение. & Разведена преди и обвьрзана сега \\
\hline 11 & $\begin{array}{l}\text { Съпругът (сьпругата) Ви какъв (каква) } \\
\text { е по професия и работи ли тук? }\end{array}$ & Машинен инженер/конструктор \\
\hline 12 & $\begin{array}{l}\text { Съпругът (съпругата) Ви българин (бъл- } \\
\text { гарка) ли е? } \\
\text { Тук ли се запознахте и оженихте или } \\
\text { пристигнахте от България вече семейни? } \\
\text { Имате ли деца? Къде са родени те? }\end{array}$ & $\begin{array}{l}\text { Да, българин е. Запознахме се тук и имаме } \\
\text { деца от предишните си разтрогнати вече } \\
\text { семейни връзки, родени в България }\end{array}$ \\
\hline 13 & $\begin{array}{l}\text { Съпругът (съпругата) Ви не е българин } \\
\text { (българка). Откъде е? } \\
\text { Тук ли се запознахте и оженихте или на } \\
\text { друго място, преди да дойдете тук? } \\
\text { Имате ли деца? Къде са родени те? }\end{array}$ & - \\
\hline 14 & $\begin{array}{l}\text { На какъв език разговаряте вкъщи? } \\
\text { А) със съпруга/сьпругата? } \\
\text { Б) с децата? } \\
\text { В) с други членове на семейството? }\end{array}$ & $\begin{array}{l}\text { Само на български помежду си, освен } \\
\text { в случаите, когато имаме чуждестранни } \\
\text { гости (рядко) }\end{array}$ \\
\hline
\end{tabular}




\begin{tabular}{|c|c|c|}
\hline 15 & $\begin{array}{l}\text { Имате ли тук българска компания и кол- } \\
\text { ко често се събирате? }\end{array}$ & $\begin{array}{l}\text { Имаме компания, с която се събираме } \\
\text { средно поне по веднъж в месеца }\end{array}$ \\
\hline 16 & $\begin{array}{l}\text { Имате ли тук български колеги и среща- } \\
\text { те ли се в извънаботно време? }\end{array}$ & Нямам такива засега \\
\hline 17 & $\begin{array}{l}\text { Когато дойдохте, знаехте ли езика на } \\
\text { страната, в която сега живеете и на } \\
\text { какво ниво? }\end{array}$ & $\begin{array}{l}\text { Познанията ми бяха ограничени, на ниско } \\
\text { ниво }\end{array}$ \\
\hline 18 & $\begin{array}{l}\text { През какъв период се връщате в Бълга- } \\
\text { рия и за колко време? }\end{array}$ & $\begin{array}{l}\text { В началото на два пъти през } 9 \text { години, } \\
\text { след което вече на всеки две }\end{array}$ \\
\hline 19 & $\begin{array}{l}\text { Поддържате ли връзка с роднини и прия- } \\
\text { тели в България и как? } \\
\text { А) по телефона? } \\
\text { Б) чрез електронната поща? } \\
\text { В) чрез писма по пощата? } \\
\text { Г) по какъв друг начин? }\end{array}$ & $\begin{array}{l}\text { И то много активна, отначало с писма, } \\
\text { после чрез телефони, а в последно време } \\
\text { и с помощта на по-новите технологии } \\
\text { - E-Mails, Skype }\end{array}$ \\
\hline 20 & $\begin{array}{l}\text { Следите ли българската преса по } \\
\text { интернет и колко често? } \\
\text { А) ежедневно? } \\
\text { Б) от време на време? } \\
\text { В) никога? }\end{array}$ & Никога не се занимавам с това \\
\hline 21 & $\begin{array}{l}\text { Гледате ли тук българска телевизия? } \\
\text { Слушате ли българско радио? }\end{array}$ & $\begin{array}{l}\text { Българска телевизия не гледам директно, } \\
\text { но най-активно следя българските филми } \\
\text { и сериали, предавани през Интернет, } \\
\text { а радио - не }\end{array}$ \\
\hline 22 & Четете ли български книги? & $\begin{array}{l}\text { Не чета на български, но много } \\
\text { интензивно на английски }\end{array}$ \\
\hline 23 & $\begin{array}{l}\text { Гостуват ли Ви тук приятели и близки от } \\
\text { България, през какъв период и за колко } \\
\text { (приблизително) време? }\end{array}$ & Родителите ни бяха на гости за 3 месеца \\
\hline 24 & $\begin{array}{l}\text { Посещавали ли сте тук българско учили- } \\
\text { ще (откога докога)? } \\
\text { Децата Ви посещават ли (посещавали ли } \\
\text { са) тук българско училище? } \\
\text { Внуците Ви посещават ли (посещавали } \\
\text { ли са) тук българско училище? } \\
\text { Децата на Ваши познати българи посе- } \\
\text { щават ли тук българско училище? } \\
\text { Ако имате възможност, бихте ли се } \\
\text { записали (бихте ли записали децата си) } \\
\text { в българско училище? } \\
\text { Защо? }\end{array}$ & $\begin{array}{l}\text { Аз лично никога, но децата ми посещаваха } \\
\text { занятията най-редовно, дорде не } \\
\text { пораснаха. } \\
\text { Само децата на някои приятели } \\
\text { посещаваха училището - вероятно за } \\
\text { други това не представляваше достатъчен } \\
\text { интерес. } \\
\text { Ако имам достатъчно малки деца } \\
\text { неминуемо бих ги записала за класни } \\
\text { занимания в българското училище } \\
\text { - независимо къде са родени, те си остават } \\
\text { БъЛГАРЧЕТА. А щом са такива, то те } \\
\text { трябва да си знаят майчиния/родния език }\end{array}$ \\
\hline & Благодаря за отделеното време! & $\begin{array}{l}\text { Вашите отговори ще помогнат на } \\
\text { българското езикознание за изследване } \\
\text { на българския език извън България. }\end{array}$ \\
\hline
\end{tabular}


Выпреки отсъствието на имена в принтираните листове и в получените отговори по пощата, анкетата в този вид не гарантираше пълна анонимност, за което си дадох сметка, след като на моите 400 писма молби откликнаха само 50 души, по-точно 20, чиито адреси можех да проследя, ако искам, а на другите 30 анкетата беше дадена в лични срещи на ръка. Резултатите от тази Първа анкета ще бъдат анализирани в сравнение с резултатите от анкетите на българи от цял свят, които видоизмених и проведох по-късно. Тук ще коментирам отговора на жителите на Сидни само на един от зададените въпроси: „На какъв език разговаряте вкъщи (със съпруга/та; с децата; с други членове на семейството)?“.

На този въпрос отговори са дали 37 от анкетираните лица. Тъй като в останалата си част отговорите на всичките 50 души са сравнително пълни, предполагам, че са изпуснали да кажат най-важното - на какъв език разговарят в семейството, защото отговорът не е еднозначен. Това личи и от устните им отговори: „както дойде“, „зависи от ситуацията“, което значи, че понякога говорят на български, а друг път на английски. Има и по-разширени отговори, например „На български, но напоследък все по-често на английски“ и „Бих искала да кажа български, но децата отговарят на английски“. Или „С дъщерята говоря на български, но внуците не знаят български и с тях говоря на английски“. Това всъщност е истинският отговор, който съвпада и с моите преки наблюдения. Иначе 37-те отговора на този въпрос са от три части, на трите отделни подвъпроса. От отговорилите 37 - 30 души заявяват, че с партньора си разговарят на български език, един - на френски (с партньор французин), един на немски (с партньор немец), един на гръцки (с партньор грък) и четирима - на английски. Трима от последните имат партньори австралийци и само един - българин. От 30-те души, заявили, че със съпругите/съпрузите си разговарят на български, има трима от смесени семейства - с ливанец, иракчанин и виетнамец. Запознах се и с трите семейства, в които чуждестранните съпрузи са наши студенти. Наистина помежду си говорят на български. Запознах се и със семейството, в което двама българи разговарят помежду си на английски. Те обясниха, че го правят за бъдещето на децата си.

Най-сигурният начин в бъдещето на децата им да има и българско влияние е наличието на баба и дядо. В Сидни живеят много възрастни родители, пристигнали „по български“ на стари години да си отгледат внуците и останали за отглеждане от децата си в чуждата страна. Затова има и подвъпрос „На какъв език разговаряте с други членове на семейството?““. Отговор на този въпрос (от 37-те въобще отговорили) са дали 22-ма души. Останалите нямат други членове на семействата си. 19 от тях посочват български и 3-ма английски. Последните се отнасят за смесените бракове на попадналите в австралийски семейства българи, т.е. семейства, в които „другите членове на семейството“ са австралийци.

Най-важната част от този въпрос е вторият подвъпрос: „На какъв език разговаряте с децата си?“. 23-ма от 37-те отговорили, от 50-те анкетирани, 
посочват, че говорят с децата си на български, което, както и да го погледнем, си е по-малко от половината. Трима посочват други езици (един - френски, един - немски и един - гръцки). От останалите 11 отговорили двама посочват, че говорят и на български, и на английски, а 9 души заявяват, че говорят с децата си само на английски.

В тази първа анкета зададените въпроси бяха 24. Те предполагаха писмени отговори (както се вижда от посочения в табл. 1 пример), което затрудняваше както попълването, така и обработката след това. Поради личните ми контакти с анкетираните много от въпросите бяха коментирани между мене и тях при други срещи или в момента. След завръщането си от Австралия разширих малко въпросите и те станаха 31. Създадох нова, Bтора анкета. Въпросите от нея, заедно с отговорите на един, произволно избран участник, представям в табл. 2:

Таблица 2. АНКЕТЕН ЛИСТ ЗА БЪЛГАРИ, ЖИВЕЕЩИ В ЧУЖБИНА

\begin{tabular}{|c|c|}
\hline Въпроси & Примерни отговори \\
\hline 1 & 2 \\
\hline 1. Къде живеете в момента (град, държава)? & ............Едмънтън, Канада................... \\
\hline 2. От колко време живеете в чужбина? & Б) между пет и десет години \\
\hline $\begin{array}{l}\text { 3. Живели ли сте другаде в чужбина и за } \\
\text { колко време? }\end{array}$ & А) по-малко от пет години; \\
\hline $\begin{array}{l}\text { 4. Откъде сте дошли от България, от коя } \\
\underline{\text { част? }}\end{array}$ & А) североизточната \\
\hline 5. Възраст & Б) между 30 и 50 години \\
\hline 6. Пол & Б) Мъж \\
\hline $\begin{array}{l}\text { 7. Образование (каква степен) и къде } \\
\text { е получено? }\end{array}$ & Д) едно в България, друго в чужбина \\
\hline 8. Професия & $\begin{array}{l}\text { А) в областта на техническите специалности } \\
\text { и/или информационни технологии }\end{array}$ \\
\hline $\begin{array}{l}\text { 9. С каква работа сега изкарвате прехраната } \\
\text { си? }\end{array}$ & А) работя по специалността си \\
\hline $\begin{array}{l}\text { 10. Семейно положение (съжителството } \\
\text { с партньор приемам за семейство) } \\
\end{array}$ & Б) женен/омъжена за българин/българка \\
\hline $\begin{array}{l}\text { 11. Съпругът (съпругата) Ви работи ли } \\
\text { и къде? }\end{array}$ & А) работи в града, в който живеем заедно \\
\hline 12. Кьде се запознахте и оженихте (сьбрахте)? & А) пристигнахме от България вече семейни \\
\hline $\begin{array}{l}\text { 13. Имате ли деца до } 20 \text { години, които са } \\
\text { с Вас в чужбина? Колко на брой? }\end{array}$ & В) имам две деца \\
\hline 14. Къде са родени и израснали децата Ви? & Б) в чужбина, където сега живеем \\
\hline
\end{tabular}




\begin{tabular}{|c|c|}
\hline$\underline{1}$ & 2 \\
\hline 15. На какъв език разговаряте с децата си? & А) на български \\
\hline $\begin{array}{l}\text { 16. На какъв език разговаряте с партньора/ } \\
\text { партньорката си? }\end{array}$ & А) на български \\
\hline $\begin{array}{l}\text { 17. На какъв език разговаряте с други } \\
\text { членове на семейството си (родители, братя, } \\
\text { сестри, роднини)? }\end{array}$ & А) на български \\
\hline $\begin{array}{l}\text { 18. Имате ли, в страната, в която живеете, } \\
\text { приятели (или колеги) българи и колко често } \\
\text { се събирате? }\end{array}$ & $\begin{array}{l}\text { Г) имам, събираме се на два-три месеца } \\
\text { веднъж }\end{array}$ \\
\hline $\begin{array}{l}\text { 19. През какъв период от време се връщате } \\
\text { в България? }\end{array}$ & $\begin{array}{l}\text { Г) на повече от три години веднъж, до десет } \\
\text { години }\end{array}$ \\
\hline $\begin{array}{l}\text { 20. Поддържате ли връзка с роднини и прия- } \\
\text { тели в България и как? }\end{array}$ & В) да, по интернет и по телефона \\
\hline $\begin{array}{l}\text { 21. Следите ли българската преса по интер- } \\
\text { нет и колко често? }\end{array}$ & Г) да, веднъж месечно \\
\hline 22. Гледате ли българска телевизия? & Д) не, никога \\
\hline 23. Слушате ли българско радио? & Б) да, от време на време \\
\hline 24. Четете ли български книги? & Д) не, никога \\
\hline $\begin{array}{l}\text { 25. Посещавали ли сте българско училище } \\
\text { в чужбина? }\end{array}$ & $\begin{array}{l}\text { В) не, поради липса на нужда, завършил/а } \\
\text { съм училище в България }\end{array}$ \\
\hline $\begin{array}{l}\text { 26. Детето/децата Ви посещава/т ли (посе- } \\
\text { щавало/и ли е/са) българско училище } \\
\text { в чужбина? }\end{array}$ & $\begin{array}{l}\text { Е) не, защото няма/т време за още един } \\
\text { ангажимент }\end{array}$ \\
\hline $\begin{array}{l}\text { 27. Други деца в семейството Ви (внуци, } \\
\text { племенници) посещават ли (посещавали ли } \\
\text { са) българско училище? } \\
\end{array}$ & В) не, но ще го/ги запишат, щом порасне/ат \\
\hline $\begin{array}{l}\text { 28. Децата на Ваши познати българи посе- } \\
\text { щават ли тук българско училище? }\end{array}$ & А) да \\
\hline $\begin{array}{l}\text { 29. Доволни ли сте от резултатите по } \\
\text { български език, постигнати в българското } \\
\text { училище от Вас лично, от резултатите на } \\
\text { децата си или на други български деца от } \\
\text { Вашето обкръжение? } \\
\end{array}$ & $\begin{array}{l}\text { Е) на този етап не, но се надявам в бъдеще } \\
\text { програмите, учебниците и преподавателите } \\
\text { да са на по-високо ниво }\end{array}$ \\
\hline $\begin{array}{l}\text { 30. Вашето семейство има ли намерение да } \\
\text { се върне някога да живее в България? }\end{array}$ & $\begin{array}{l}\text { Д) не, но човек никога не знае какво ще } \\
\text { стане в бъдеще }\end{array}$ \\
\hline 31. Какво е за Вас България? & Д) държава, в която имам роднини \\
\hline Благодаря за отделеното време! & $\begin{array}{l}\text { Вашите отговори ще помогнат на } \\
\text { българското езикознание за изследване } \\
\text { на българския език извън България! }\end{array}$ \\
\hline
\end{tabular}


Тази анкета беше разпратена по интернет до всички краища на света със съдействието на фирма „Теза“, в която работя, заедно с електронен учебник по български език за чужденци, създаден от екип професионалисти. Автор на текста съм аз [Исса 2018]. В анкетата само първият въпрос „Къде живеете в момента (град, държава)?“ изисква писмен отговор. На останалите 30 въпроса са посочени по няколко примерни отговора, от които анкетираният може да избере един. Попълването е изцяло on-line и става лесно и бързо. Анонимността е гарантирана. Отговорите пристигат при мене в момента на завършването на анкетата, без да имам никаква представа от кого ${ }^{1}$.

След пьрвоначалната обработка въпросът за местожителството на българите, които са попълнили анкетата, е изяснен. За периода 21.03. - 23.11.2017 г., т.е. за срок от осем месеца, съм получила 184 отговора. Седем от тях изключвам от коментар - те са или празни, или невалидни поради взаимоизключващи се отговори, т.е. налице е грешка/засечка. От останалите 177 отговора 169 са от 23 различни държави, а 8 са с неустановено местожителство (анкетираното лице не е пожелало да посочи местонахождението си, но е отговорило на другите въпроси). Както се вижда от табл. 3 , в която е спазен азбучният ред, по който имената на държавите са подредени, активността от различните страни е различна:

Таблица 3. МЕСТОЖИТЕЛСТВО НА АНКЕТИРАНИТЕ ЛИЦА

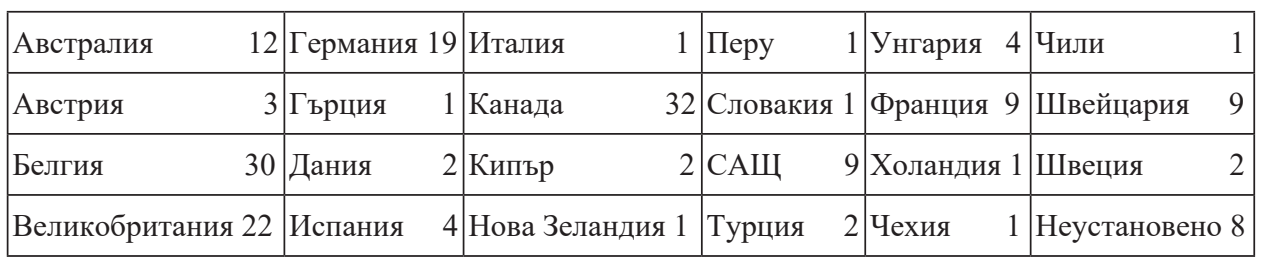

Най-много отговори са получени от Канада (32), последвани от Белгия (30) и Великобритания (22). Има 12 отговора и от Австралия, 6 от които са от Сидни, от хора, с които не съм успяла, за съжаление, да се запозная по време на своя престой ${ }^{2}$.

Целта на проведената Bтора анкета не съвпада с целта на настоящия доклад. Тук ще бъдат коментирани отговорите на три въпроса, единствено

\footnotetext{
${ }^{1}$ Позволявам си и тук да посоча линка, тъй като очаквам още отговори от сънародници: http://onlinebulgarian.teza.bg/goto.php?target=svy_139\&client_id=bgcourse

${ }^{2}$ След проведената научна конференция в Лодз получих още две попьлнени анкети от Полша, които ще бъдат включени към наличните досега и коментирани в различни аспекти в научната ми работа. Искрено благодаря на колегите българи, които навярно са присъствали и откликнали светкавично на моята молба да се включат те самите (в случай че живеят извън България) и да разпространят анкетата и сред други българи, живеещи в чужбина. Използвам случая да повторя молбата си пред всеки, който чете тези редове, тъй като продължавам да очаквам отговори на посочения по-горе линк.
} 
за да се видят нагласите на емигрантите към предаването на езика ни на поколенията и към българските училищза зад граница. Следващата стьпка, възпрепятствана от времето за представяне на един доклад и обема на една статия, е да се потърсят връзките на тези нагласи със социално-демографските характеристики на анкетираните лица - на първо място с времето, през което живеят в чуждата страна, живели ли са в друга държава преди и колко време, от коя част на България са дошли. Получените отговори ще бъдат съотнесени към възрастта на анкетираните лица, за да се види коя възрастова група повече държи за запазване на родния ни език; към техния пол, като се има предвид грижата предимно на българската майка за възпитанието на децата; към образованието на анкетираните и дали то е получено у нас или в чужбина; към професията, доколкото нагласите за използване или не на езика се влияят от професионалния интерес на хората; към работата, с която те изкарват прехраната си зад граница (дали е престижна и дава самочувствие и право на избор, или временна и изтощителна, което влияе негативно върху волята да се превключва непрекъснато кода в процеса на общуване с децата). Получените отговори ще бъдат коментирани и във връзка със семейното положение на анкетираните лица: на първо място - дали семействата са изцяло български или смесени, дали при смесените партньорът е от страната приемник, дали си е „у дома“ или е от друга, но трета страна; дали съпрузите са пристигнали от България заедно или са се запознали и събрали на новото място; и, разбира се, дали имат деца, къде са родени те и посещават ли българско училище. В анкетата има въпроси за обкръжението на анкетираните - дали имат приятели българи и колко често се събират, през какъв период от време се връщат в България, дали поддържат връзка с роднини и приятели у нас - фактори, които биха повлияли значително на поддържането на езика ни жив или на пълното блокиране на неговите функции. Има въпроси и за интереса към живота в страната ни - дали се следи пресата, телевизията, радиото, дали се четат български книги.

Първият въпрос, който тук ще разгледам, е с номер 15 и гласи „На какъв език разговаряте с децата си?“‘. Примерните отговори към него са шест:
А) на български
Б) на езика на страната, в която живеем сега
В) на чужд език, но друг, не официалния за страната, в която живеем сега
Г) на български и на официалния език на страната, в която живеем
Д) на български и на друг, чужд за страната, в която живеем, език
Е) на езика на страната, в която живеем, плюс още един чужд език

Резултатите са повече от задоволителни. Точно 100 души посочват отговор A, т.е. те говорят с децата си на български. Този голям процент вероятно не е съвсем реален, но да не забравяме, че щом изследваме структурата на нагласите, дори и в сферата на пожелателното да бъде поставен, отговорът показва недвусмислено твърдото намерение на българите да запазят езика си и да го предадат на своите потомци. Отговор Б са дали само 7 анкетирани 
лица, т.е. те признават, че говорят с децата си на официалния език на страната, в която живеят. Двама от анкетираните, вероятно от смесени семейства, посочват отговор В - те говорят с децата си на чужд език, но друг, не официалния за страната, в която живеят. Най-близо до реалното състояние, като се има предвид, че нагласите представляват вероятност индивидът да покаже специфично поведение в специфична ситуация, стои отговор Г, получен от 35 анкетирани лица. Те заявяват, че говорят с децата си както на български, така и на официалния език на страната, в която живеят. За съжаление, възможностите на анкетния метод свършват тук и само теренно проучване може да установи кой от езиците преобладава. По един от последните два отговора са дали двама от анкетираните, а 31 не са отговорили на този въпрос. Специално сверих техните отговори на предишните два въпроса и установих, че те нямат деца.

Вторият от въпросите, който предлагам за коментар, е с номер 26: „Детето/децата Ви посещава/т ли (посещавало/и ли е/са) българско училище в чужбина?“. Примерните отговори към него са седем:

А) да, посещава/т в момента

Б) да, посещавал/а/и е/са като дете/деца училището в страната, където живеем сега

В) не, но ще го/ги запиша, щом порасне/ат

Г) не, поради липса на нужда, завършил/а/и е/са училище в България

Д) не, поради липса на желание, няма/т нужда от българско образование

Е) не, защото няма/т време за още един ангажимент

Ж) не, защото наблизо няма българско училище

Резултатите от отговорите на тозивъпроснесатака полюсно противоположни. С равен брой са неотговорилите (41 души) и отговорилите, че децата им посещават българско училище в момента (също 41 души). Ако си припомним предишния въпрос, на който не отговориха 31 души (онези, които нямат деца) може да предположим, че останалите 10 вероятно не са в ученическа възраст, въпреки че за това има други примерни отговори. Например отговор Б, получен от 23 анкетирани лица, показва, че децата им са посещавали училище, но са го завършили, т.е. те са вече големи. Отговор В, получен от 11 души, показва наличието на малки деца в някои семейства и, по-важно, показва положителната нагласа на тези семейства към българското училище и намерението да запишат децата си, щом пораснат. За децата на възраст над ученическата, които са заминали след завършване на училище в България, свидетелства отговор Г, получен от 15 души. Вероятно някои (или всичките 10) липсващи отговора се отнасят до деца, които не са заминали със семействата си, а са останали в България при баби и дядовци, при други роднини, или сами, ако вече са големи. За съжаление, има и такива семейства, които мислят, че децата им нямат нужда от българско образование. Това се вижда от отговор Д, получен от 12 души. Отговор Е е получен също от 12 души и показва, че децата не ходят на училище, защото нямат време за още един ангажимент. Следователно, въпреки еднаквия резултат - децата на 
24 семейства не посещават българско училище - тук не можем да говорим за еднакви нагласи, защото само пьрвата е негативна. Втората, може би възпитано омекотена, а може би обективна, показва грижа към безбройните ангажименти и умора на децата, което не значи, че отхвърля българското образование. Доста тъжна е констатацията в последния отговор, Ж, получен от 22 анкетирани лица. Те заявяват, че децата им не посещават училище, защото наблизо няма българско училище. Разбира се, в анкетата няма как да определим относителността на фактора разстояние, силата на желанието за обучение в българско училище, степента на владеене на български език, която всьщност е определяща за мотивацията на самите деца да посещават или не училище $\mathrm{e}^{3}$.

Въпросът за отношението към училището е зададен по принцип, но той всъщност се отнася конкретно към местното неделно училище, което анкетираните познават, както и към обучението по български език в страната, в която живеят. Решаването на този въпрос би трябвало да бъде първостепенна грижа на учителите, на правителството, за училищата на територията на България, и особено за откритите през последните години български училища извън пределите на България. Тук когнитивните компоненти на нагласите би трябвало да стоят в оценъчната скала над афективните и мотивационните, а изследователите и управляващите в нашата страна да имат ясното съзнание, че качеството на българското образование предопределя до голяма степен и поведенческите нагласи на анкетираните лица, както и мотивите (желание/нежелание за посещаване на училището) на техните/нашите деца.

Отношението към училището е изследвано чрез въпрос номер 29, „Доволни ли сте от резултатите по български език, постигнати в българското училище от Вас лично, от резултатите на децата си или на други български деца от Вашето обкръжение?“. Примерните отговори са:

А) да, говоря/т български, и благодарение на училището

Б) да, но не харесвам/т преподавателите

В) да, но не харесвам/т учебниците

Г) да, но времето не стига, трябва да се учи повече дни в седмицата

Д) не, няма смисъл от обучение в българско училище

Е) на този етап не, но се надявам в бъдеще програмите, учебниците и преподавателите да са на по-високо ниво

${ }^{3}$ По време на престоя си в Сидни разговарях с много деца на българи, които категорично отказват да посещават българското училище. Отношението към българския език и българското образование на нито едно от тях не беше отрицателно. Те уважаваха родината на своите родители (без да я припознават като своя единствена, но я приемаха като втора) и с охота се кичеха с нашите национални символи: видях на снимка след спортно състезание българското знаме, обгърнало раменете на победителя, видях мартеници, сурвачки и значки с българския герб, които тези деца носеха. Но те не знаеха български език! Затова не искаха да ходят в неделното училище - „за да не се излагат“, да не си губят времето, след като нищо не разбират, да не се затормозяват с още един ангажимент. Те и техните родители не вярваха, че е възможно българският език да се усвои в училището. За съжаление имаха право... 
Отговорите на този въпрос предполагат общи впечатления, както лични, от собственото обучение на по-младите българи, израснали в чужбина, така и от това на децата и внуците на анкетираните лица, на техни роднини, приятели и познати. Затова е учудващо, че в сравнение с другите два въпроса, неотговорилите на този выпрос са най-много - 42-ма души. Анкетираните, които мислят, че децата говорят български и благодарение на училището са 62-ма, посочили отговор А, което показва положителната нагласа като цяло към българското образование и изучаването на езика ни в частност. Прави впечатление императивното отношение към обучението, в отговор Г, получен от 27 анкетирани лица. Те смятат, че времето за обучение трябва да се увеличи, без да отчитат възможностите за това, но и този отговор показва положителна нагласа към българското образование. Същата нагласа се вижда и от отговор E, получен от 22-ма анкетирани. Те, въпреки че на този етап не харесват обучението, имат надежда (съответно и положителна нагласа) за подобряване на ситуацията в бъдеще. Негативни нагласи имат само пет от анкетираните лица. Те смятат, че няма смисъл от българско образование (отговор Д). Отговор Б показва чисто субективното отношение на петима души, които не харесват преподователите, защото вероятно имат предвид конкретни преподаватели. Учудващо мальк е броят на анкетираните, които заявяват, че не харесват учебниците (14 души, дали отговор В). Понеже познавам учебниците, по които се преподаваше през учебната 2016/2017 година в Сидни, мисля, че повечето възрастни хора не ги познават, защото не са си направили труда да ги прегледат. Това показва доверие в авторите на учебниците, одобрени от МОН в България. За съжаление нито авторите, нито институциите заслужават такова доверие. Състоянието на учебниците е плачевно, но тук няма да бъде коментирано, защото съм го представила подробно в друго изследване [Исса 2016].

В заключение, характеристиката на нагласите на българските емигранти към родния език и родното образование зад граница е ценна по отношение на бъдещата работа на българското езикознание и на българските образователни институции, за които основен приоритет трябва да бъде забавянето на процеса на отродяване на българите в чужбина и на забравянето на българския език от поколенията. Всяка проява на грижа от страна на държавата и на езиковата ни политика би променяла и нагласите по посока към родното, тъй като те не са изначални и неизменяеми. Следователно дейността или бездействието на институциите в изоставената родина може да формира нагласите в зависимост от заинтересоваността или липсата на заинересованост към живота на емигрантите. Мотивирани от нашата дейност, нагласите на емигрантите могат да се превърнат в мотивиращи действия - те самите да работят за разпространението на българския език и култура по света, за изучаването на езика и традициите ни и предаването им на поколенията. Само ако не сме безучастни към този наболял проблем, можем да се надяваме на нагласи за завръщане в родината или поне обмисляне на възможности за съпринадлежност от страна на емигрантите. Ние в България имаме безспорната нагласа да ги чакаме... 


\section{Библиография}

Алексова Кр. (2016), Социиолингвистична периепџฺи, езикови нагласи и социилна идентификация по речта, Парадигма, София.

Байчев Б., М. Виденов (1988), Социолингвистическо проучване на град Велико Търново, АБАГАР, София.

Виденов М. (1990), Съвременната българска градска езикова ситуация, УИ „Св. Кл. Охридски“, София.

Исса К. (2016), Австралийски бележки. За нашето Слово в големия свят. [в:] „, Светът е слово. Словото е свят “. Сборник с доклади от юбилейна национална конференция с международно участие, посветена на 25 години Филологически факултет 2016, Благоевград, c. $519-527$.

Исса К. (2018), Откриваме сами българския език. Електронен учебник, достъпен на следния интернет адрес: https://onlinebulgarian.com/

\section{Катя Исса}

\section{ATTITUDES OF TODAY'S BULGARIAN EMIGRANTS TO THEIR NATIVE LANGUAGE AND BULGARIAN EDUCATION ABROAD}

(Summary)

The attitudes of the numerous Bulgarian emigrants, scattered across the continents, to our language and to his use abroad are of particular importance for the Bulgarian state and language policy regarding emigration.

The two questionnaires were conducted among the Bulgarian emigrant community in Sydney, Australia on one side and worldwide (where the answers came from) on the other side. In this report are commented the results of both questionnaires. Only those answers that reflect the attitudes of today's emigrants to the use of their native Bulgarian language in daily communication and their willingness to participate in Bulgarian education abroad of their children are analyzed here.

The characteristics of the attitudes of Bulgarian emigrants to their native language and Bulgarian education abroad are valuable in terms of the future work of Bulgarian linguistics and Bulgarian governmental institutions. Their main priority should be the delay of the process of forgetting the Bulgarian language from the generations.

Key words: questionnaire survey, language attitudes, priorities of the state language policy 